We are working on visiting Syrian refugees who fled to Jordan and Lebanon.

- Plans to help colleagues in Misrata, Libya. Mental health workers have been overwhelmed by the number of referrals of patients with mental health problems following the events that took place there.
- Arranging workshops/lectures in trauma management via electronic means or in person if required.

The BAPA is also working with colleagues from the other diaspora associations in the UK to form the Great Partnership Council, possibly with some joint working with the College.

Dr Nadim Almoshmosh, President of the BAPA

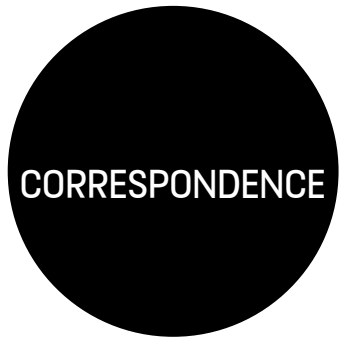

Correspondence should be sent to ip@rcpsych.ac.uk

\section{The experience of stigma among a sample of psychiatric in-patients in an Egyptian private psychiatric hospital}

Sir: We examined the emotional, behavioural and cognitive effects of having a psychiatric diagnosis on in-patients in an Egyptian psychiatric hospital. We also examined whether this effect changes with specific disorders, duration of illness or sociodemographic variables.

A structured interview was prepared to enquire into aspects of stigma; it comprised 37 yes/no questions with a common prefix, After knowing that you have a psychiatric problem.... The study sample comprised 109 consecutively admitted patients ( 87 men and 22 women) who were willing to participate. Patients with organic disorders, intellectual disabilities or gross thought disorders rendering them unfit to participate were excluded. The two interviewers had an interrater reliability of 0.91 (kappa test).

The mean participant age was 36.1 years and mean illness duration was 5 years. The ICD-10 diagnoses were schizophrenia and related psychoses $(n=48)$, substance use disorders $(n=28)$, mood disorders $(n=28)$, personality disorders $(n=4)$ and neurosis $(n=1)$

Of the 37 questionnaire items, those attracting affirmative responses from $60 \%$ or more of the participants were considered as core items of stigmatisation. They were (with the percentage of the sample endorsing the item):

- Do you need faith or traditional healing (89\%)?

- Do you need to help yourself $(85 \%)$ ?

- Do you think others would urge you to consult religious clergy $(81 \%)$ ?

- Do you feel sorry for yourself $(78 \%)$ ?

- Are you unable to have peace of mind $(75 \%)$ ?

- Do you need others' help (73\%)?

- Do you feel something is wrong with yourself $(72 \%)$ ?

- Are others surprised about your state (68\%)?

- Have others reduced their contact with you $(68 \%)$ ?

- Are you anxious about your future (67\%)?

Younger age correlated with more feelings of stigmatisation and unpleasant fantasies about others' reactions. People with no or low education had unpleasant fantasies about others' reactions. Patients with schizophrenia and related disorders were more stigmatised by others' behaviour towards them and had more unpleasant fantasies about others' reactions.

The majority affirmed their need for help from others besides psychiatric intervention and that psychiatric labels were not of significance to them. People with schizophrenia and related disorders and mood disorders perceived stigmatisation regarding others' behavioural change towards them (other people were surprised to know the patient had psychiatric problems, reduced their contact with them, urged them to have faith, urged them to have nothing to do with psychiatrists, or gave them fewer responsibilities).

A mean total stigma score was calculated for all patients. Those with schizophrenia, substance misuse and mood disorders had similar average scores.

The underrepresentation of female patients in psychiatric services could be attributed to the protective effect of culture.

This study highlights the significance of stigma in relation to mental illness and the overarching societal need to tackle this issue in order to improve access to services and outcomes for patients.

\section{E. Sidhom ${ }^{1}$, A. Abdelfattah ${ }^{2}$, A. R. El-Dosoky ${ }^{3}$,}

\section{J. M. Carter ${ }^{4}$ and M. F. El-Islam ${ }^{5}$}

${ }^{1}$ Registrar in Psychiatry, Behman Hospital, Cairo, Egypt, email e.sidhom@gmail.com; ${ }^{2}$ Specialist in Psychiatry, Behman Hospital; ${ }^{3}$ Consultant Psychiatrist, Managing Director, Behman Hospital; ${ }^{4}$ Statistical Analyst, Behman Hospital; ${ }^{5}$ Academic Consultant, Behman Hospital

\section{Study of the mental health problems of war-affected youths in northern Uganda}

Sir: Survivors of war are at increased risk of mental health problems (Amone-P'Olak et al, 2007; Wessels, 2009). Although many studies have been conducted in Africa on war-affected youths, they are fraught with major weaknesses.

First, they have been mainly cross-sectional yet the effects of war are long term, and so generalisation of their findings is limited and causal inferences are difficult to make. Second, they have lacked control groups, and so the specific effects of war experiences are difficult to distinguish. Third, war-affected populations have been treated as a homogeneous group, without regard to differences in age, gender and experiences. Fourth, 
most of these studies have not considered individual, family and community risk factors and protective factors. Fifth, most of the assessment scales used were developed and validated in the West, and are thus of uncertain cultural sensitivity and appropriateness.

In addition, there is a lack of sustainable local systems to respond to the mental health needs of war-affected people. Most study services were provided by foreign researchers and non-governmental organisations (NGOs). Consequently, the indigenous resources to respond to the war were left untapped. As a result, little remains to show after the foreign researchers and NGOs have left.

A longitudinal research project has been started at Gulu University, the only institution of higher learning in northern Uganda; it is funded by the Wellcome Trust. The WAYS study (War-Affected Youth Survey) aims to investigate the long-term course of mental health problems in war-affected youths using a longitudinal design and social ecology model. It is inspired by a study by Betancourt et al (2010) in Sierra Leone. It is being conducted in collaboration with the University of Cambridge but at Gulu University it will help build local capacity and ensure the sustainability of services.

The longitudinal design will allow for recruitment of controls, and locally derived and validated questionnaires will be used to collect data. Heterogeneity of the population will be considered and all analyses will be carefully checked for differences associated with age, gender and war experiences.

The effects of war experiences and risk and protective factors will be assessed within the framework of a three-level social ecological model (Bronfenbrenner, 1979). The model allows examination of the individual, family and community factors responsible for long-term mental health problems in war-affected youths, thus addressing both the individual and social ecology (Boothby, 2008). Studies that have focused on only one level have underestimated the effects of other contexts (Stokols, 1996).

Participants are people aged 18-35 who were abducted and lived in captivity for at least 6 months. The first study wave (assessment) ended in September 2011; the second wave will be conducted from May 2012. In total, 539 youths participated in the baseline study. The study mostly used instruments which were locally developed and validated for use among former child soldiers in Africa. The standard measures were back-translated from Luo to English by experts from the Department of English of Gulu University. At baseline, information on demographic characteristics, war experiences, contextual factors and psychosocial outcomes was collected.

It is anticipated that the WAYS study will build on theory and elucidate how a confluence of factors influence post-war psychosocial adjustment. Such knowledge may inform policy and improve care. It is also anticipated that the project will develop local capacity for research and training to strengthen mental health services and guarantee sustainability.

\section{Kennedy Amone-P'Olak}

Department of Psychology, Faculty of Education and Humanities, Gulu University, Uganda, email ka387@cam.ac.uk

Amone-P'Olak, K., Garnefski, N. \& Kraaij, V. (2007) Adolescents caught between fires: cognitive emotion regulation in response to war experiences in northern Uganda. Journal of Adolescence, 30 655-669.

Betancourt, T. S., Brennan, R. T., Rubin-Smith, J., et al (2010) Sierra Leone's former child soldiers: a longitudinal study of risk, protective factors, and mental health. Journal of the American Academy of Child and Adolescent Psychiatry, 49, 606-615.

Boothby, N. (2008) Political violence and development: an ecologic approach to children in war zones. Child and Adolescent Psychiatric Clinics of North America, 17, 497-514.

Bronfenbrenner, U. (1979) The Ecology of Human Development: Experiments by Nature and Design. Harvard University Press.

Stokols, D. (1996) Translating social ecological theory into guidelines for community health promotion. American Journal of Health Promotion, 10, 282-298.

Wessells, M. (2009) Supporting the mental health and psychosocial well-being of former child soldiers. Journal of the American Academy of Child and Adolescent Psychiatry, 48, 587-590.

\section{International Congress of the Royal College of Psychiatrists}

10-13 July 2012, Liverpool

Email congress@rcpsych.ac.uk; website www.rcpsych.ac.uk/eventsandcourses/internationalcongress2012.aspx

The Congress programme strives for scientific rigour and to lead the way in developing clinical excellence and promoting best practice. We are committed to ensuring that attendees leave with an improved understanding of psychiatry and mental health and the interactions between mental health, neuroscience and the social and cultural context in which people live.

\section{Congress streams include:}

- Psychopharmacology

- Clinical skills

- Management

- Children and families
- Holistic psychiatry

- New science

- College

- Research

- Neuropsychiatry
- Teaching and training

- Global mental health

- Private practice

- Refractory psychosis

- Commissioning 